
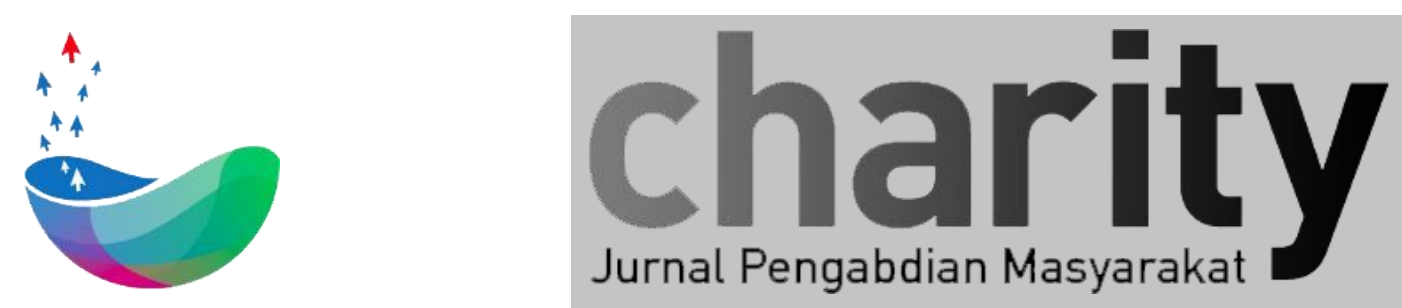

\title{
Pelatihan Keterampilan Pembuatan Sabun Cair untuk Penerapan Hidup Bersih dan Pemberdayaan Ekonomi Masyarakat
}

\author{
Memoria Rosi ${ }^{1}$, Ismudiati Puri Handayani ${ }^{2}$, Hertiana Bethaningtyas ${ }^{3}$ \\ ${ }^{1}$ Teknik Fisika, Fakultas Teknik Elektro, Universitas Telkom \\ ${ }^{2}$ Teknik Fisika, Fakultas Teknik Elektro, Universitas Telkom \\ ${ }^{3}$ Teknik Fisika, Fakultas Teknik Elektro, Universitas Telkom \\ *memoriarosi@telkomuniversity.ac.id, iphandayani@telkomuniversity.ac.id, hertiana@telkomuniversity.ac.id
}

\section{INFO ARTIKEL}

Diterima 16 September 2021

Direvisi 08 Oktober 2021

Disetujui 15 Oktober 2021

Tersedia Online 20 November 2021

\begin{abstract}
ABSTRAK
Di masa pandemi seperti sekarang ini, kesehatan dan kondisi ekonomi masyarakat perlu mendapat perhatian lebih. Sebagaimana masyarakat umum lainnya, warga Desa Citeureup juga merasakan dampak pandemik ini. Sebagian warga ada yang terinfeksi Covid 19 dan sebagian lagi kehilangan pekerjaan atau usahanya harus dihentikan akibatnya adanya pembatasan maupun menurunya jumlah omset usahanya. Berdasarkan pertimbangan tersebut, Tim Dosen Teknik Fisika Universitas Telkom melakukan pengabdian masyarakat di RW 6 Desa Citeureup. Kegiatan dilakukan dalam bentuk survey untuk memetakan persoalan di masyarakat, pemasangan tempat cuci tangan, dan pelatihan keterampilan pembuatan sabun cair. Hasil survey menunjukkan bahwa masyarakat secara umum terdampak oleh Covid 19 dan menginginkan adanya bantuan agar mereka memiliki usaha sendiri. Kegiatan ini diharapkan menjadi kampanye peningkatan kesadaran masyarakat akan pentingnya kebersihan dan kesehatan, transfer pengetahuan tentang pembuatan sabun cair, dan inisiasi kemandirian ekonomi masyarakat desa Citeureup.
\end{abstract}

Keyword: pelatihan sabun cair, kebersihan, pemberdayaan ekonomi.

Korespondensi:

Direktorat Penelitian dan Pengabdian Masyarakat, Universitas Telkom)

Jl. Telekomunikasi No. 1, Terusan Buah Batu, Bandung, 40257)

Indonesia

E-mail : ppm@telkomuniversity.ac.id

ORCID ID: 0000-0002-1598-5266

Penulis Pertama: Memoria Rosi

https:// 10.25124/charity.v4i2a

Paper_reg_number xxx (C) The Authors. Published by Directorate of Research and Community Service, Telkom University.

This is an open access article under the $\mathrm{xxx}$ license (https://creativecommons.org/licenses/xxx) 


\section{Pendahuluan}

Dampak pandemik tidak hanya dirasakan masyarakat dari sisi kesehatan namun juga dari sisi ekonomi. Data statistik menunjukkan bahwa laju perekonomian masyarakat menurun dan jumlah masyarakat miskin bertambah sejak pertengahan 2020 hingga sekarang [Biro Pusat Statistik, 2021]. Oleh sebab itu, pemberdayaan dan pendampingan masyarakat perlu dilakukan agar masyarakat bisa mandiri secara ekonomi maupun kesehatan.

Salah satu upaya pemberdayaan dan pendampingan masyarakat yang dilakukan oleh Teknik Fisika Unversitas Telkom adalah melaksanakan Program Pengabdian Masyarakat di Desa Citeureup yang berada berada di Kecamatan Dayeuh Kolot Kabupaten Bandung dan berjarak 4,9 km dari Universitas Telkom. Desa ini terdiri atas 4 dusun dan 17 RW. Luas wilayah desa Citeureup 203 Ha [Desa Citeurep, 2021]. Letak desa Citeureup disekitar Kawasan Industri Dayeuh Kolot pada posisi 115.7.20 LS 8. 7.10 BT, dengan ketinggian kurang lebih $250 \mathrm{~m}$ diatas permukaan laut. Akibatnya pada musim hujan sebagian daerah terdampak banjir.

Warga desa Citeureup mayoritas lulusan sekolah menengah atas dengan kondisi perekonomian cenderung menengah ke bawah serta sebagian besar warga berprofesi sebagai wiraswasta, pedagang, dan pekerjaan lain yang cenderung tidak berpenghasilan tetap[Desa Citeureup, 2021]. Permasalahan utama masyarakat Desa Citeureup adalah ekonomi dan lingkungan yang kurang baik. Dalam masa pandemi ini kondisi ekonomi masyarakat makin sulit, khususnya bagi yang tidak berpenghasilan tetap. Hal ini mengakibatkan tingkat perekonomian desa menurun.

Sabun sebagai salah satu kebutuhan dasar masyarakat harganya cukup mahal bagi masyarakat yang memiliki pendapatan setara dengan UMR Kabupatan Bandung. Perlu adanya program program pemberdayaan masyarakat khususnya ibu rumah tangga tanpa profesi tetap agar kondisi kesehatan dan ekonomi keluarganya lebih baik. Program itu harus sederhana dan disesuaikan dengan kemampuan dan waktu yang dimiliki para ibu rumah tangga tersebut. Untuk itu perlu pendekatan terus menerus melalui aktifitas sederhana yang menyenangkan dan secara ekonomi berpotensi untuk menambah pendapatan masyarakat.

Fokus kegiatan pengabdian masyarakat ini adalah 15 kader PKK dan 15 kader Karang Taruna di RW 6 Desa Citeureup. Kegiatan berfokus pada upaya memetakan persoalan masyarakat, memasang tempat cuci tangan, pelatihan sabun, dan memotivasi warga untuk mulai memasarkan sabun. Sebelum kegiatan ini, mereka pernah berpartisipasi di Program PHP2D dan Innovillage Teknik Fisika. Mereka bisa menjadi percontohan perintis bagi warga lain. Selain itu pengurus RW juga bersedia untuk diajak kerja sama memobilisasi masyarakat.

\section{Metode}

Kegiatan pengabdian masyarakat ini dapat dibagi atas lima tahapan diantaranya: 


\subsection{Inisiasi Kegiatan Pengabdian Masyarakat}

Tahapan pertama yang dilakukan adalah survey ke lokasi Desa Citeureup dan menemui pengurus RW dan tokoh masyarakat. Pada tahap ini diperoleh informasi tentang kondisi masyarakat, tingkat pendidikan dan masalah rendahnya pengetahuan masyarakat tentang kebersihan. Secara garis umum, kebutuhan masyarakat dapat dipetakan dalam tiga hal yaitu pendidikan, kesehatan dan ekonomi.

\subsection{Pengadaan Fasilitas Cuci Tangan}

Solusi pertama yang dilaksanakan adalah pengadaan fasilitas umum cuci tangan yang diletakkan di depan balai desa. Setelah tempat cuci tangan dipasang, kegiatan pengabdian masyarakat dilanjutkan dengan memberikan penyuluhan tentang bagaimana menjaga kebersihan dengan sering mencuci tangan dengan sabun. Warga setempat pun mempraktekkan cara cuci tangan yang benar.

\subsection{Pelatihan Pembuatan Sabun}

Kegiatan selanjutnya yang dilakukan adalah penyuluhan dan praktek pembuatan sabun mulai dari pengenalan bahan-bahan, alat yang dibutuhkan, takaran yang digunakan dan pembagian sabun secara cuma-cuma. Kepada warga juga dijelaskan dimana tempat membeli sabun, biaya sabun dan estimasi keuntungan yang bisa diperoleh jika memproduksi sabun sendiri.

Pembuatan sabun membutuhkan alat pengaduk rakitan sederhana, wadah pengadukan sabun dan bahan-bahan sabun. Proses pembuatan sabun berlangsung selama sekitar 60 menit yang dapat menghasilkan lebih dari 60 L sabun cair siap pakai. Adapun komposisi bahan sabun yang digunakan dapat dilihat di Tabel 1.

Tabel 1. Bahan dan komposisi sabun

\begin{tabular}{|c|c|}
\hline Bahan & Kuantitas \\
\hline Texapon & $5 \mathrm{~kg}$ \\
\hline Water glass & $2 \mathrm{~L}$ \\
\hline Foom & $2 \mathrm{~L}$ \\
\hline $\mathrm{NaCl}$ & $5 \mathrm{~kg}$ \\
\hline Parfum & $1 \mathrm{~L}$ \\
\hline Akuades & $60 \mathrm{~L}$ \\
\hline
\end{tabular}


Adapun langkah pembuatan sabun cair adalah

a. Menyiapkan semua alat dan bahan

b. Menyiapkan campuran pertama yang terdiri dari texapon sebanyak $5 \mathrm{~kg}$ yang dicampur dengan parfum sebanyak $1 \mathrm{~L}$ kemudian ditambahkan akuades sebanyak 1. Campuran diaduk sampai rata

c. Menyiapkan campuran kedua yaitu $\mathrm{NaCl}$ sebanyak $5 \mathrm{~kg}$ yang dicampur dengan water glass sebanyak 2 L kemudian ditambahkan air sebanyak 1 L. Campuran diaduk sampai rata

d. Menyiapkan campuran ketiga yaitu foam sebanyak $2 \mathrm{~L}$ dan akuades sebanyak $1 \mathrm{~L}$ sambil diaduk sebentar

e. Tuang campuran pertama dan kedua kemudian ditambahkan akuades sebanyak 2 L sambil diaduk kembali

f. Masukkan pula campuran ketiga dengan menambahkan $1 \mathrm{~L}$ akuades

g. Sabun cair selesai dibuat

h. Pengemasan sabun pada wadah-wadah yang sudah disiapkan.

\subsection{Diskusi dengan Peserta Pelatihan Sabun}

Selama pelatihan pembuatan sabun, kami membuka diskusi dengan peserta. Beberapa peserta cukup aktif merespon mengajukan pertanyaan selama kegiatan pelatihan ini terkait dengan cara pengadukan dan komposisi sabun yang digunakan. Setelah pelatihan sabun selesai, warga melakukan pengisian kuisioner untuk mengetahui lebih jauh tentang kondisi mereka dan umpan balik kegiatan pengabdian masyarakat ini.

\subsection{Wawancara dengan Tokoh Masyarakat}

Selain diskusi dengan warga, juga dilakukan wawancara dengan tokoh masyarakat setempat untuk berdiskusi tentang manfaat pelatihan yang dilaksanakan maupun rencana keberlanjutan pengabdian masyarakat ke depan.

\section{Hasil dan Pembahasan}

Dokumentasi rapat koordinasi dengan pengurus RW dan perwakilan warga serta pelatihan pembuatan sabun ditampilkan pada Gambar 1. (a) dan (b). Hasil koordinasi menunjukkan bahwa pengurus RW 6 dan tokoh masyarakat menyambut baik program pengabdian masyarakat ini. Ada 10 warga hadir mengikuti pelatihan sabun. Selain merasa perlu untuk belajar membuat sabun mereka juga merasa perlu adanya fasilitas cuci tangan pada masa pandemi ini. 


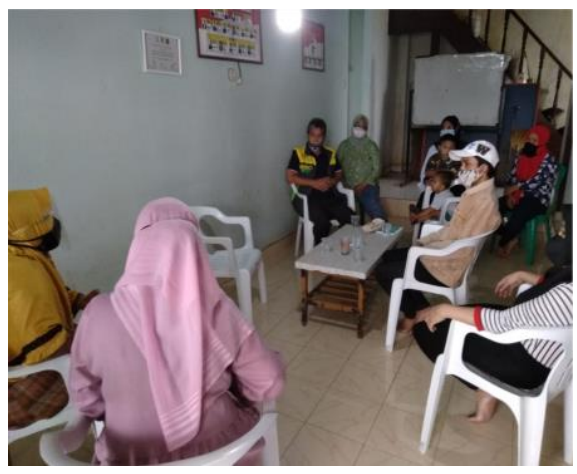

(a)

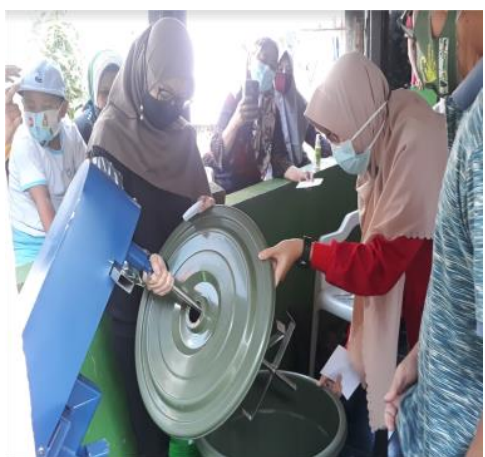

(b)

Gambar 1. (a) Pertemuan koordinasi dengan pengurus RW dan perwakilan warga (b) Pelatihan pembuatan sabun

Hasil produk sabun dan praktik cuci tangan ditampilkan pada Gambar 2. (a) dan 2. (b). Hasil pembuatan sabun dibagikan ke masyarakat sedangkan tempat cuci tangan diletakkan pada 3 tempat yang banyak digunakan oleh masyarakat yaitu balai pertemuan RW, masjid, dan fasilitas green house hidroponik.

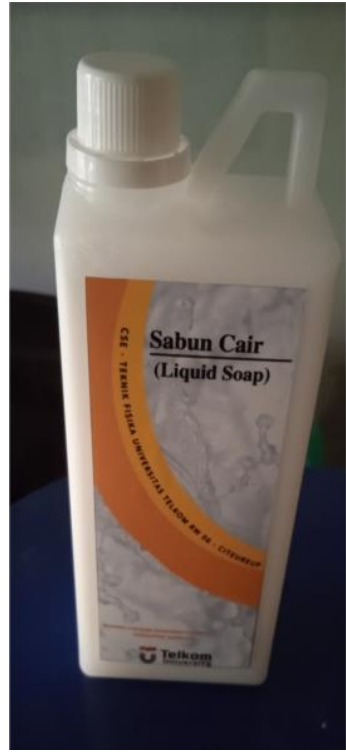

(a)

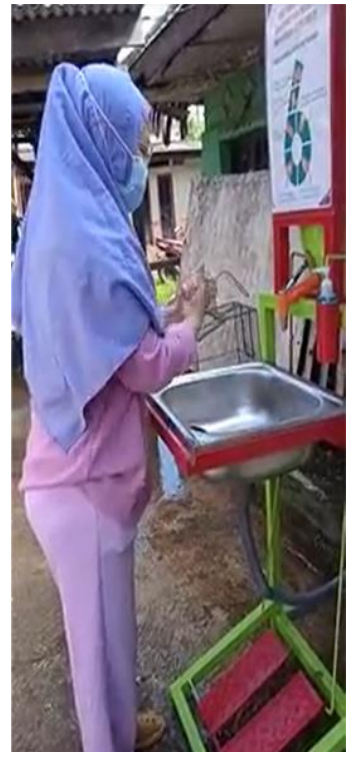

(b)

Gambar 2. (a) Produk sabun hasil pelatihan (b) Praktik mencuci tangan

Agar kondisi masyarakat dapat dipetakan dengan lebih baik, peserta pelatihan juga diminta mengisi kuisioner yang hasilnya ditampilkan pada Gambar 3 - 4. Gambar 3. (a) menunjukkan bahwa $89 \%$ peserta menyatakan ada salah satu anggota keluaga yang pernah terkena Covid 19. Namun hanya $44 \%$ peserta pelatihan yang 
menyatakan pernah mengikuti penyuluhan tentang Covid -19 seperti ditunjukkan oleh Gambar 3. (b). Hal ini menunjukkan bahwa masih perlu upaya-upaya penyuluhan kesehatan agar masyarakat dapat beradaptasi dengan kondisi pandemi saat ini.

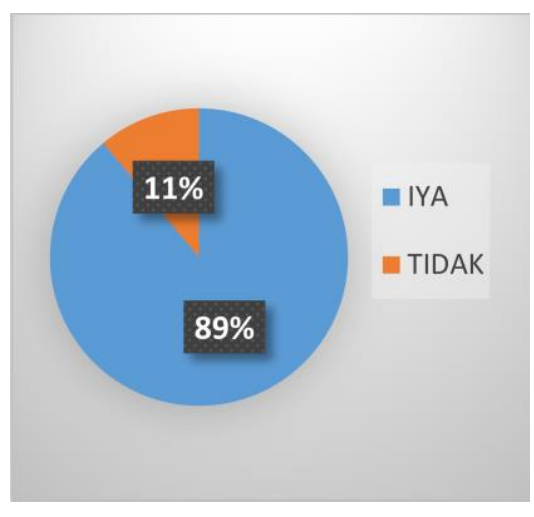

(a)

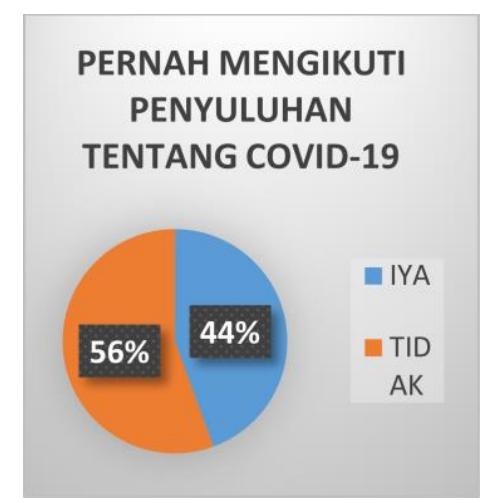

(b)

Gambar 3. (a) Prosentase anggota keluarga yang terpapar covid. (b) Prosentase warga yang pernah mengikuti penyuluhan Covid-19

Terkait dengan program pembuatan sabun, $89 \%$ peserta pelatihan menyatakan berminat belajar membuat sabun dan $11 \%$ masih belum tahu apakah berminat atau tidak (Gambar. 4. (a)). Selain itu $80 \%$ peserta pelatihan juga berfikir bahwa dengan belajar membuat sabun (Gambar 4. (b)), ekonomi keluarga dapat terbantu dan $100 \%$ peserta pelatihan berminat menjual sabun (Gambar 4. (c))

Selama berlangsungnya acara juga terjadi diskusi dua arah dari tokoh masyarakat, masyarakat peserta dan pelaku UMKM di lingkungan sekitar. Diskusi tidak hanya terbatas pada pengetahuan tentang bahan sabun dan proses pembuatan saja, namun juga meluas pada inisiasi penjualan sabun untuk menstimulasi ekonomi masyarakat desa. Jika dilihat dari potensi penjualan, bahan pembuat sabun ini tergolong murah dan mudah ditemukan. Apalagi sabun cair ini memiliki beberapa kelebihan diantaranya mudah dibuat, waktu pembuatan lebih singkat, harga bahan dasar sabun yang lebih hemat jika dibandingkan dengan sabun batang.

Kegiatan pengabdian masyarakat ditutup dengan wawancara dengan tokoh masyarakat, evaluasi masyarakat berupa lembar kuisioner. Berdasarkan hasil wawancara dan evaluasi dari peserta, masyakat sangat senang dengan adanya acara ini. Menurut mereka pelatihan ini sangat bermanfaat dan merupakan hal yang baru mereka dapatkan. Masyarakat juga antusias untuk mendapatkan pelatihan-pelatihan serupa tentang kesehatan terutama di masa pandemi ini. Di samping itu mereka juga 
menyatakan keinginan yang besar untuk mengimplementasikan pengetahuan yang mereka dapatkan untuk kebutuhan sendiri dan penjualan untuk kemandirian ekonomi masayarakat desa Citeurep sendiri.

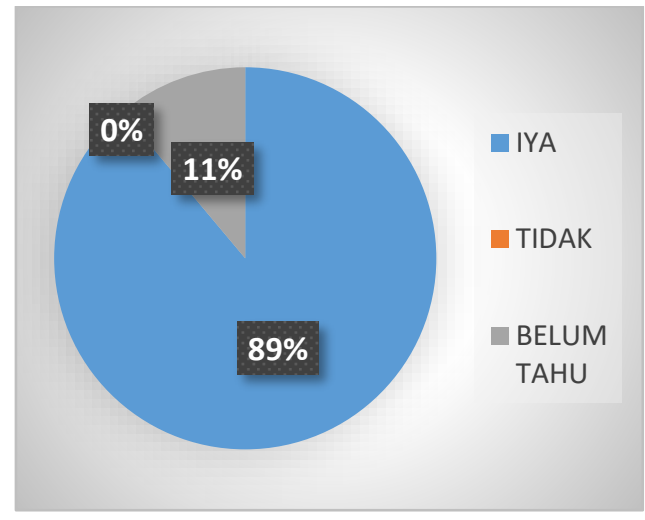

(a)

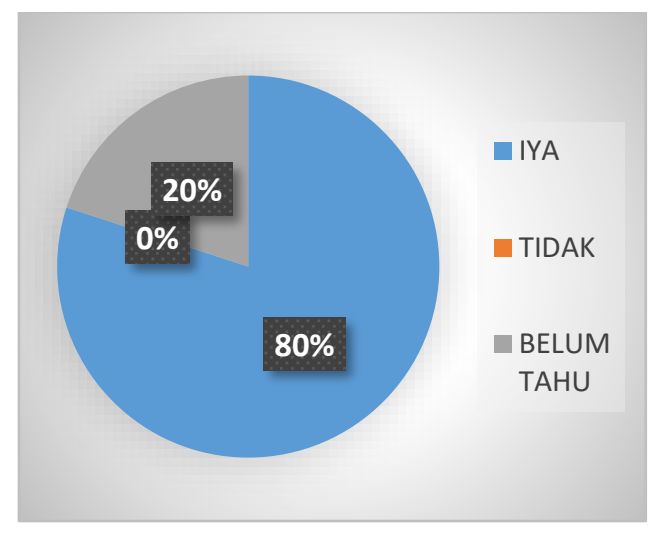

(b)

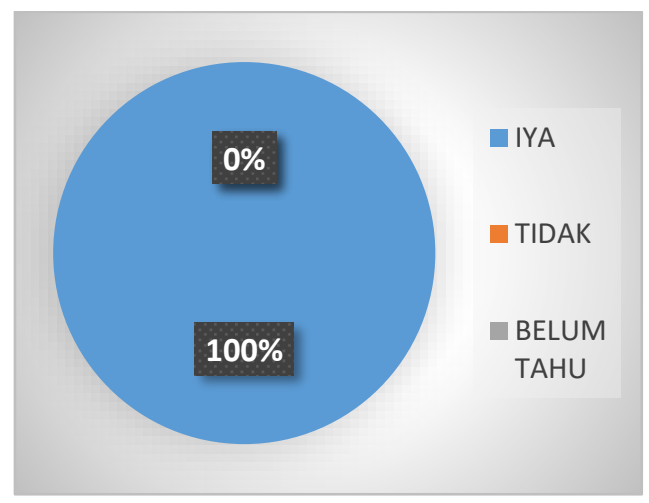

(c)

Gambar 4. Prosentase masyarakat yang merasa (a) perlu untuk belajar membuat sabun, (b) sabun dapat membantu ekonomi keluarga, dan (c) berminat menjual sabun 


\section{Kesimpulan dan Saran}

Kegiatan pengabdian masyarakat disambut baik oleh masyarakat dan sudah sesuai dengan kebutuan masyarakat Desa Citeureup. Sebagian besar peserta pelatihan memiliki keluarga yang pernah terinfeksi Covid-19 namun baru sebagian kecil yang pernah mendapatkan penyuluhan tentang Covid-19 dan hidup sehat. Sebagain besar peserta pelatihan juga beminat menjual sabun sebagain alternatif membantu perekonomian keluarga

Kegiatan pengabdian masyarakat perlu ditindaklanjuti dengan melibatkan lebih banyak warga Desa Citeureup. Resep sabun perlu ditambahkan bahan organik yang menghasilkan sabun yang aman dan ramah lingkungan. Selain itu perlu dilakukan pengujian sabun berstandar SNI agar layak untuk dipasarkan.

\section{Ucapan Terima Kasih}

Penulis mengucapkan terima kasih kepada PPM Universitas Telkom yang telah memberikan dukungan finansial agar kegiatan pengabdian masyarakat ini dapat berlangsung dengan baik. Terima kasih juga disampaikan kepada Ketua RW 6 Desa Citeureup dan seluruh masyarakat setempat yang telah membuka kerjasama yang baik sehingga kegiatan pengabdian masyarakat ini terselenggara dengan lancar.

\section{DAFTAR PUSTAKA}

[1] Biro Pusat Statistik, "Profil Kemiskinan di Indonesia," 2021. [Online]. Available: https://www.bps.go.id/website/images/Kemiskinan-Maret-2021-ind.jpg

[2] Desa Citeureup, "Data Demografi," 2021. [Online]. Available: https://citeureupbandung.desa.id/first/wilayah

[3] Citeureup, "Grafik Pekerjaan Warga Desa Citeureup," 2021. [Online]. Available: https://citeureup-bandung.desa.id/first/statistik/1 